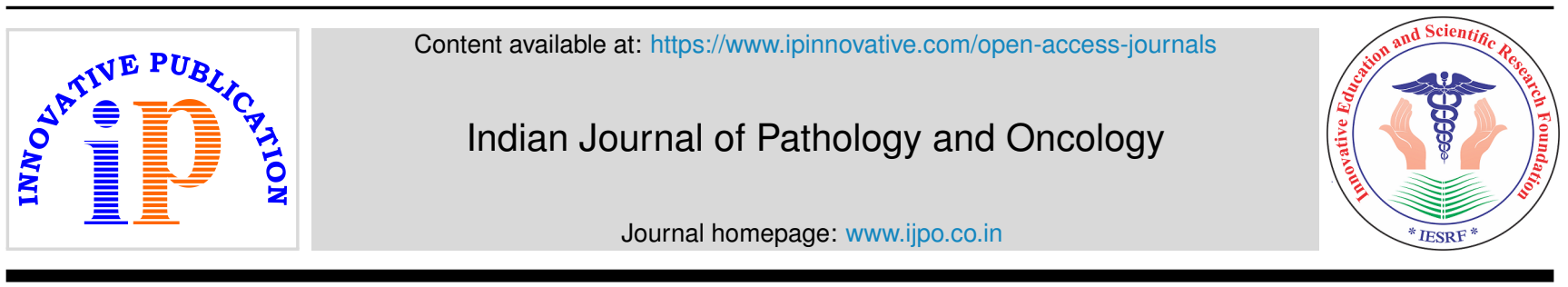

\title{
Review Article \\ Immunohistochemical analysis of ki 67 in breast carcinoma- A survey in Indian population
}

\author{
S Sabhari Priya ${ }^{1, *}$, Sandhya Sundaram ${ }^{1}$, Karunagaran $^{2}$, V Pavithra ${ }^{1}$ \\ ${ }^{1}$ Dept. of Pathology, Sri Ramachandra Institute of Higher Education and Research, Chennai, Tamil Nadu, India \\ ${ }^{2}$ Dept. of Biotech, Indian Institute of Technology Madras, Chennai, Tamil Nadu, India
}

\section{A R T I C L E I N F O}

Article history:

Received 12-03-2020

Accepted 31-08-2020

Available online 19-11-2020

\section{Keywords:}

Breast cancer

Biomarkers

Hormone receptors

Ki- 67

Immunohistochemistry

\begin{abstract}
A B S T R A C T
Background: Breast cancers are widely prevalent in females worldwide and their diagnosis is effectively facilitated by the analysis of various hormone receptors and certain biomarkers. One of the key biomarkers is the proliferation marker $\mathrm{Ki}-67$ which is a nucleoprotein used for predicting these cancers. This study was carried out to analyse the pattern of presentation of Ki-67 in breast cancer.

Materials and Methods: This cross-sectional, retrospective, record based study was carried out among 100 resected breast cancer specimens. Haemotoxylin and Eosin stained slide cut from formalin fixed paraffin wax embedded, resected specimens of breast carcinoma were analyzed. The histological diagnosis of tumor was diagnosed as per WHO classification. The positive or negative immunohistochemical expression of Estrogen, progesterone and Androgen receptors in addition were evaluated using standard protocol. Ki-67 expression was also analyzed and correlated with the hormonal receptor presentation.

Results: Ki-67 was graded as $<14 \%$ and $>14 \%$. Significantly high expression of Ki-67 was witnessed in $61 \%$ of the specimens. As far as the other biomarkers were examined, negative expressions of ER, PR, Her2neu and AR were strongly correlating to Ki-67 expression $(90.5 \% .86 .8 \%, 81.1 \%$ and $100 \%$ ) respectively. However, the observed difference was statistically not significant when compared to the other biomarkers but statistically significant as an independent prognostic marker.

Conclusion: Our study has succinctly elaborated that Ki-67 can be used as an efficient and independent biomarker to determine the survival outcomes of breast cancers. Considering its role in establishing therapeutic protocols, further research is required to evaluate the impact of Ki-67 expression at the molecular level.
\end{abstract}

(C) This is an open access article distributed under the terms of the Creative Commons Attribution License (https://creativecommons.org/licenses/by/4.0/) which permits unrestricted use, distribution, and reproduction in any medium, provided the original author and source are credited.

\section{Introduction}

India in recent times has been witnessing a paradigm shift in the incidence of diseases from infectious diseases to noncommunicable diseases including malignancies. Among the various malignancies, breast cancer has been one of the most common cancers in Indian females with age adjusted rate as high as 25.8 per hundred thousand women. The disease not only rapid but also results in very high mortality rate of 12.7 per hundred thousand women. ${ }^{1}$ The population- based cancer registries had shown that

\footnotetext{
* Corresponding author.

E-mail address: sabharipriya91@gmail.com (S. S. Priya).
}

major cities including Delhi, Chennai, Bengaluru are highly susceptible for such cancers, indicating the role of diet and lifestyle in the incidence of breast malignancies. Although several published works indicate that breast cancer is common in the perimenopausal age group, the recent trend has witnessed its incidence in younger women, especially at around 30 years of age. The clinical outcome and prognosis of breast cancer is highly dependent on the time of detection and the stage of disease. Early detection of the cancer has significantly resulted in better outcomes, early improvement and increased survival rates. ${ }^{2}$

There are several biomarkers which assist in the definitive diagnosis of breast cancer. Predominantly, the 
biomarkers include estrogen receptor, progesterone receptor and androgen receptor and in addition her2neu receptor which also has been said to play a significant role in identifying the pathognomonic features of the cancer and also aiding as a predictor for survival outcomes. Moreover, these biomarkers are useful in predicting the relapse rates thereby proving to be novel tool for diagnosis. One of the key biomarkers is $\mathrm{Ki} 67$ the proliferation marker which is a nucleoprotein used for predicting the cancers. Ki-67 was first expressed in Hodgkin Lymphoma. It is associated with cellular proliferation and is expressed in S, G1, G2 and $M$ phase of cell cycle. In addition, $\mathrm{Ki}-67$ is included in oncotype DX as they are used for predicting the risk of recurrence and extent of chemotherapy benefits in women with negative or estrogen receptor (ER) positive breast cancer. $^{3,4}$

Although there are several studies that have explored the prognostic role of $\mathrm{Ki}-67$ in breast cancer, its presentation in combination with presence of other biomarkers including ER, PR, AR and Her2neu has been rarely explored, especially in Indian subset of population. A detailed exploration of the presentation and pattern of occurrence of these biomarkers will help in developing an algorithm for early detection of breast cancer and also help in prospective development of modelling which will predict survival outcomes of breast cancer in women.

\section{Objectives}

This study was carried out to evaluate the pattern of presentation of $\mathrm{Ki}-67$ in breast cancer.

\section{Materials and Methods}

\subsection{Study setting and participants}

This cross-sectional record-based study was carried out in the Department of Pathology of a tertiary teaching institution for a period of 18 months between January 2017 and July 2018.

\subsection{Study participants}

All the resected specimens which were received during the study period with a diagnosis of breast carcinoma were taken up for this study. A total of 100 specimens were analysed in this study.

\subsection{Ethical approval}

Ethical approval was obtained from the Institutional Ethics Committee prior to the commencement of the study.

\subsection{Data collection}

Haemotoxylin and Eosin stained slide cut from formalin fixed paraffin wax embedded, resected specimens of breast carcinoma were analyzed. The histological diagnosis of the tumor was diagnosed as per WHO classification of breast $4^{\text {th }}$ edition.

The constructed blocks were recut, deparaffinised and rehydrated in alcohol. Antigen retrieval was conducted using a Citrate buffer and the sections were incubated at $3 \%$ hydrogen peroxide for a period of 5 minutes and then incubated for 60 minutes at room temperature with mouse monoclonal primary antibodies against ER, PR, Her2/neu and $\mathrm{Ki}-67$. Immuno reaction was visualized by adding DAP. Internal positive controls were normal breast detect epithelia for ER and PR. External positive controls were ER, PR and Her2neu positive breast carcinoma for each of these biomarkers respectively. Grading was carried out according to the pattern of membranous staining and percentage of stain malignant cells as $0,<10 \%$ of the cells (1), faint or incomplete staining in $>10 \%$ of the cells (2), complete staining in $>10 \%$ of the cells (3) and strong complete staining in $>10 \%$ of the cells. ${ }^{5}$

Immunostaining of $\mathrm{Ki}-67$ was done using $\mathrm{Ki}-67$ monoclonal antibody (antihuman Ki-67 analogue AM 297 - 5M Biogenex) at a dilution of 1:50.Ki-67 index was calculated as the cancer cells positively stained by Ki-67 (percentage). For positive control, lymph node section was used. A presence of nuclear staining of the tumor cells was taken as positive staining. Sections were examined under HPF to observe distinct immunoreactivity in 1000 cancer cells. Area with high density of immunostained nuclei was considered as hot spot. Hot spot areas were selected and adjacent fields upto 1000 nuclei were counted. This was expressed as mean. A negative control (without addition of primary antibody) was included in every batch of immunostaining.

\subsection{Data entry and analysis}

Data was entered and analyzed using SBSS Version 20 software. The Ki67 values were expressed as percentage of positive cells in each case and $\mathrm{Ki}-67>14 \%$ were categorized as high expression. The comparison between positivity of other biomarkers in relation to $\mathrm{Ki}-67$ was carried out using Chi-squared test. The p-value less than 0.05 were considered statistically significant.

\section{Results}

This record based cross-sectional study was carried out among 100 specimens received in our tertiary care hospital. Majority of the participants were over 50 years of age $(65 \%)$ and were diagnosed with invasive mammary carcinoma (73\%). Grade 2 was the most common presentation of breast carcinoma (45\%). (Table 1)

The biomarker status of all the specimens were analysed. It was observed that Estrogen Receptor (ER) was positive in $23 \%$ of the specimens, while progesterone receptor (PR) 
was positive in $31 \%$ of the specimens. Similarly, Her2neu was positive in $27 \%$ of the specimens. Ki-67 was graded as $<14 \%$ and $>14 \%$. Significantly high expression of Ki-67 was witnessed in $61 \%$ of the specimens. (Table 2)

Several factors including the grading and biomarkers were correlated with $\mathrm{Ki}-67$ expression in our study. It was observed that, all the specimens showing grade 1 were positive for Ki-67 expression (100\%). As far as the other biomarkers were examined, negative ER, PR, Her2neu and AR were strongly correlating to $\mathrm{Ki}-67$ expression (90.5\%. $86.8 \%, 81.1 \%$ and $100 \%)$ respectively. However, the observed difference was statistically not significant. (Table 3)

\section{Discussion}

Breast cancer is one of the most common cancers affecting the females worldwide and its incidence and mortality rates are high in developing countries like India owing to various diet and lifestyle factors. It is essential that techniques for early diagnosis and treatment of breast cancers are in place for enhancing the survival outcomes of these females over the next 5 years following diagnosis.

As far as the diagnosis for breast cancer goes the standard protocol involves assessment and grading of the malignancy based on the histological diagnosis followed by the evaluation of certain biomarkers including the hormonal receptor presentation. Biomarker analysis is widely carried out for all cancers and has helped in identification of the cardinal features of the cancer and also helps in planning the due course of treatment by weighing the risks and benefits of such hormone-based treatments. In breast cancer the most common biomarkers analyzed include the estrogen receptor, progesterone receptor and androgen receptor. In addition, we also evaluate the human epidermal growth factor receptor 2 (HER-2 neu). Approximately 30 to $40 \%$ of the patients who express the presence of these hormonal receptors generally likely to have better prognosis with hormonal replacement therapy following surgical resection and/or chemo or radio therapy. ${ }^{6}$ Similar to such bio markers the recent research has identified the presence of $\mathrm{Ki}-67$ as one of the important prognostic marker for breast cancer.

In our study we evaluated the pattern and presentation of a various bio markers among 100 resected specimens of breast cancer. Majority of the participants were over 50 years of age and grade 2 was common presentation of breast cancer. Our study revealed that only $23 \%$ of the specimens were positive for estrogen receptor and the $31 \%$ were positive for progesterone receptor. Ki-67 was evaluated in our study and high expression of Ki-67 was found in $61 \%$ of the specimens. Our study observed that Ki67 over expression was predominantly associated when the hormone receptors were negative.

$\mathrm{Ki}-67$ is usually expressed in the proliferative phase of the cell cycle. In normal breast tissues, $\mathrm{Ki}-67$ is expressed in very low levels $(<3 \%) .^{7}$ The expression increases progressively across the continuation from benign breast tissue to ductal carcinoma to in situ cancers to invasive breast cancers. Therefore, the presence of expression $\mathrm{Ki}$ 67 in a breast issue indicates an advanced stage or invasive malignancies which stems out of mutation in the p53 oncogene. ${ }^{8} \mathrm{Ki}-67$ can hence be used as an independent predictor of breast cancer especially when the hormonal receptors are negative.

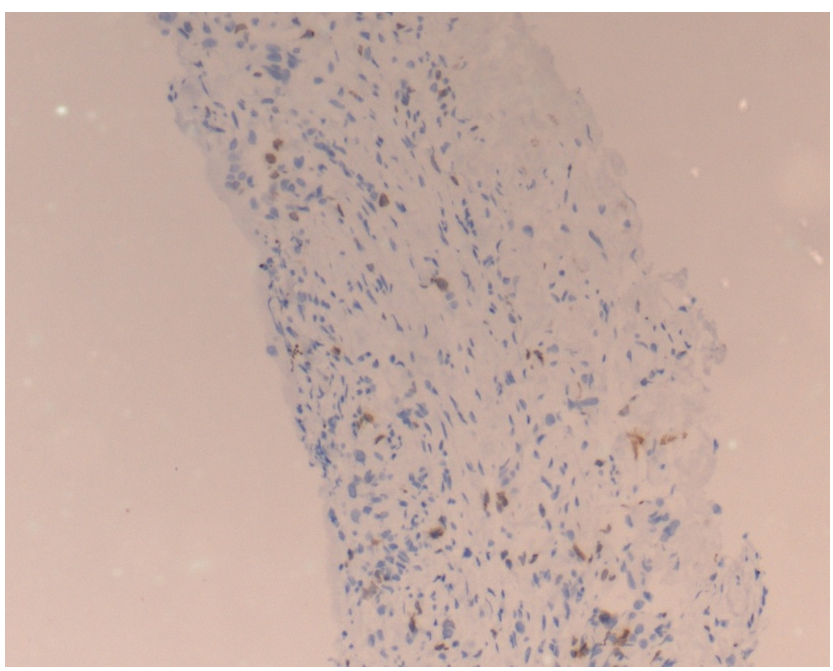

Fig. 1: Nuclear immunohistochemical staining for $\mathrm{Ki} 67$ in invasive breast carcinoma. Ki 67 staining is $10 \%$

\section{Ki 67-90\%}

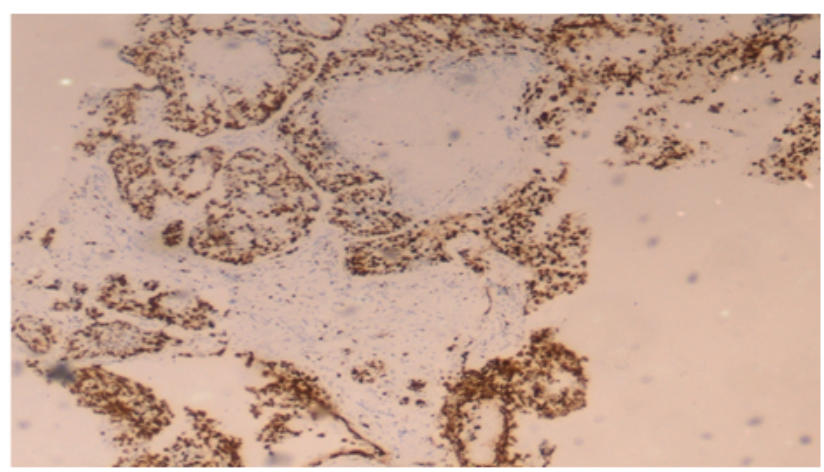

Fig. 2: Nuclear staining for $\mathrm{Ki} 67$ is $90 \%$ in a case of invasive mammary carcinoma

Our study demonstrated that Ki-67 is increasingly expressed in ER and PR negative tumors. Similar findings were observed in studies done by HM Ragab et al. and which did not show statistically significant correlation between the hormonal status and Ki-67. Similar findings were seen in studies done by Nishimora $\mathrm{R}$ et al., Haroon $\mathrm{S}$ et al. and Spyratos F et al. ${ }^{9-11}$ 
Table 1: Background characteristics

\begin{tabular}{|c|c|c|c|}
\hline S.No & $\begin{array}{l}\text { Characteristics } \\
\text { Age (in years) }\end{array}$ & Frequency $N=100$ & Percentage $(\%)$ \\
\hline \multirow[t]{9}{*}{1} & $<50$ & 35 & 35.0 \\
\hline & $>50$ & 65 & 65.0 \\
\hline & Type of carcinoma & & \\
\hline & Bilateral invasive mammary carcinoma & 1 & 1.0 \\
\hline & Invasive mammary carcinoma & 1 & 1.0 \\
\hline & Invasive carcinoma-no spe & 2 & 2.0 \\
\hline & Invasive ductal carcinoma & 3 & 3.0 \\
\hline & Invasive ductolobular carcinoma & 4 & 4.0 \\
\hline & Invasive lobular carcinoma & 3 & 3.0 \\
\hline \multirow[t]{10}{*}{2} & Invasive mammary carcinoma & 73 & 73.0 \\
\hline & Invasive medullary carcinoma & 5 & 5.0 \\
\hline & Invasive papillary carcinoma & 1 & 1.0 \\
\hline & Invasive tubular and lobular carcinoma & 1 & 1.0 \\
\hline & Invasive tubular carcinoma & 1 & 1.0 \\
\hline & Invasive mammary carcinoma & 1 & 1.0 \\
\hline & Mucinous breast carcinoma & 1 & 1.0 \\
\hline & No evidence of carcinoma in situ & 3 & 3.0 \\
\hline & Grade & & \\
\hline & 1 & 18 & 18.0 \\
\hline \multirow[t]{3}{*}{3} & 2 & 45 & 45.0 \\
\hline & 3 & 12 & 12.0 \\
\hline & Not available & 25 & 25.0 \\
\hline
\end{tabular}

Table 2: Biomarkers status among the specimens

\begin{tabular}{|c|c|c|c|}
\hline S.No & Biomarkers & Frequency $\mathrm{N}=100$ & Percentage $(\%)$ \\
\hline & Estrogen Receptor (ER) & & \\
\hline \multirow{3}{*}{1.} & Negative & 49 & 49.0 \\
\hline & Positive & 23 & 23.0 \\
\hline & Not available & 28 & 28.0 \\
\hline \multirow{4}{*}{2.} & Progesterone Receptor (PR) & & \\
\hline & Negative & 42 & 42.0 \\
\hline & Positive & 31 & 31.0 \\
\hline & Not available & 27 & 27.0 \\
\hline \multirow{4}{*}{3.} & her2neu & & \\
\hline & Negative & 42 & 42.0 \\
\hline & Positive & 27 & 27.0 \\
\hline & Not available & 31 & 31.0 \\
\hline \multirow{5}{*}{4.} & Grade & & \\
\hline & 1.00 & 18 & 18.0 \\
\hline & 2.00 & 45 & 45.0 \\
\hline & 3.00 & 12 & 12.0 \\
\hline & Not available & 25 & 25.0 \\
\hline \multirow{4}{*}{5.} & Androgen Receptor (AR) & & \\
\hline & Negative & 14 & 14.0 \\
\hline & Positive & 49 & 49.0 \\
\hline & Not available & 37 & 37.0 \\
\hline \multirow{4}{*}{6.} & Ki-67 expression & & \\
\hline & $>14 \%$ & 61 & 61.0 \\
\hline & $<14 \%$ & 14 & 14.0 \\
\hline & Not available & 25 & 25.0 \\
\hline
\end{tabular}


Table 3: Predictors of Ki-67 among the study specimens

\begin{tabular}{|c|c|c|c|c|}
\hline \multirow{3}{*}{ S. No } & \multirow{2}{*}{ Predictors } & \multirow{2}{*}{$\mathbf{N}$} & \multicolumn{2}{|c|}{ Ki-67 n(\%) } \\
\hline & & & $>14 \%$ & \\
\hline & Age (in years) & & & \\
\hline \multirow[t]{3}{*}{1.} & $>50$ & 48 & $38(79.2)$ & $10(20.8)$ \\
\hline & $<50$ & 27 & $23(85.2)$ & $4(14.8)$ \\
\hline & Grade & & & \\
\hline \multirow{4}{*}{2} & 1 & 13 & $13(100)$ & $0(0)$ \\
\hline & 2 & 35 & $29(82.9)$ & $6(17.1)$ \\
\hline & 3 & 8 & $6(75)$ & $2(25)$ \\
\hline & ER & & & \\
\hline \multirow[t]{3}{*}{3} & Positive & 21 & $15(71.4)$ & $6(28.6)$ \\
\hline & Negative & 42 & $38(90.5)$ & $4(9.5)$ \\
\hline & PR & & & \\
\hline \multirow[t]{3}{*}{4} & Positive & 25 & $20(80)$ & $5(20)$ \\
\hline & Negative & 38 & $33(86.8)$ & $5(13.2)$ \\
\hline & Her2neu & & & \\
\hline \multirow[t]{3}{*}{5} & Positive & 26 & $23(88.5)$ & $3(11.5)$ \\
\hline & Negative & 37 & $30(81.1)$ & $7(18.9)$ \\
\hline & $\mathbf{A R}$ & & & \\
\hline \multirow[t]{2}{*}{6} & Positive & 49 & $37(75.5)$ & $12(24.4)$ \\
\hline & Negative & 14 & $14(100)$ & $0(0)$ \\
\hline
\end{tabular}

There has been substantial evidence to suggest that $\mathrm{Ki}$ 67 plays a major role in determining the prognosis and outcomes of the breast cancer. However several studies are still underway to explore the predictive role of $\mathrm{Ki}-67$ in making the right choice of chemotherapy. A study done by Penault-Lorca showed that patients with Ki67 expression of $>20 \%$ seem to have a benefit when docetaxel is used as an adjuvant in the chemotherapy for breast cancer. ${ }^{12}$ Further exploratory research in this area needs to be done to suggest a candid protocols for therapeutic management of breast cancers.

\section{Conclusion}

Breast cancers, being widely prevalent among females in India, need to be evaluated for the histopathological presentations in order to facilitate accurate diagnosis and also to predict prognosis and survival outcomes. Our study demonstrated a significantly high expression of Ki-67 in triple negative breast cancers, thereby indicating a worse prognosis. Our study has succinctly elaborated that Ki67 can be used as an efficient and independent biomarker to determine the survival outcomes of breast cancers. Considering its role in establishing therapeutic protocols, further research is required to evaluate the impact of $\mathrm{Ki}$ 67 expression at the molecular level, in coherence with the therapeutic advantages of various chemotherapeutic agents for managing breast cancers.

\section{Source of Funding}

None.

\section{Conflict of Interest}

Nil.

\section{References}

1. Malvia S, Bagadi SA, Dubey US, Saxena S. Epidemiology of breast cancer in Indian women. Asia-Pac J Clin Oncol. 2017;13(4):289-95.

2. Taneja P, Maglic D, Kai F. Classical and novel prognostic markers for breast cancer and their clinical signicance. Clin Med Oncol. 2010;4:15-34.

3. Paik S, Shak S, Tang G, Kim C, Baker J, Cronin M, et al. A Multigene Assay to Predict Recurrence of Tamoxifen-Treated, Node-Negative Breast Cancer. N Engl JMed. 2004;351(27):2817-26.

4. Paik S, Tang G, Shak S, Kim C, Baker J, Kim W, et al. Gene expression and benefit of chemotherapy in women with node-negative, estrogen receptor-positive breast cancer. J Clin Oncol. 2006;24(23):3726-34.

5. Nahed AS, Shaimaa MY. Ki-67 as a prognostic marker according to breast cancer molecular subtype. Cancer Biol Med. 2016;13(4):496504.

6. Colomer R, Aranda-López I, Albanell J, García-Caballero T, Ciruelos E, López-García MA. Biomarkers in breast cancer: A consensus statement by the Spanish Society of Medical Oncology and the Spanish Society of Pathology. Clin Transl Oncol. 2018;20(7):815-26.

7. Kontzoglou K, Palla V, Karaolanis G, Karaiskos I, Alexiou I, Pateras I. Correlation between Ki67 and Breast Cancer Prognosis. Oncol. 2013;84(4):219-25.

8. Ragab HM, Samy N, Afify M, Maksoud NAE, Shaaban HAM. Assessment of $\mathrm{Ki}-67$ as a potential biomarker in patients with breast cancer. J Genet Eng Biotechnol. 2018;16(2):479-84.

9. Nishimura R, Osako T, Okumura Y, Hayashi M, Toyozumi Y, Arima N. Ki-67:As a prognostic marker according to breast cancer subtype and a predictor of recurrence time in primary breast cancer. Exp Ther Med. 2010;1(5):747-54.

10. Haroon S, Hashmi AA, Khurshid A, Kanpurwala MA, Mujtuba S, Malik B, et al. Ki67 Index in Breast Cancer: Correlation with Other Prognostic Markers and Potential in Pakistani Patients. Asian Pac J Cancer Prev. 2013;14(7):4353-8.

11. Spyratos F, Ferrero-Poüs M, Trassard M, Hacène K, Phillips E, Tubiana-Hulin M. Correlation between MIB-1 and other proliferation 
markers. Cancer. 2002;94(8):2151-9.

12. Penault-Llorca F, Andre F, ', Sagan C. Ki67 expression and docetaxel efficacy in patients with estrogen receptor-positive breast cancer. $J$ Clin Oncol. 2009;27(17):2809-15.

\section{Author biography}

S Sabhari Priya, Post Graduate

Sandhya Sundaram, Professor and HOD
Karunagaran, Professor and HOD

V Pavithra, Assistant Professor

Cite this article: Priya SS, Sundaram S, Karunagaran, Pavithra V.

Immunohistochemical analysis of ki 67 in breast carcinoma- A survey

in Indian population. Indian J Pathol Oncol 2020;7(4):513-518. 